\title{
COVID-19 en la época de dengue
}

\author{
COVID-19 in the dengue season \\ Pío López López,* Eduardo López Medina, ${ }^{\ddagger}$ Iván Benavidez ${ }^{\S}$ \\ * Jefe del Departamento de Pediatría, Universidad del Valle. Director del Programa de Infectología Pediátrica Universidad
del Valle. Investigador Emérito de Colciencias. Presidente de la Sociedad Latinoamericana de Infectología
Pediátrica. Director General del Centro de Estudios en Infectología Pediátrica, Cali, Colombia.
‡ Profesor Asistente. Departamento de Pediatría, Universidad del Valle. Director Científico del Centro de Estudios en
Infectología Pediátrica, Cali, Colombia. Director de Infectología Pediátrica del Centro Médico Imbanaco.
\& Fellow segundo año de Infectología Pediátrica, Departamento de Pediatría, Universidad del Valle. Cali, Colombia.
}

\section{GENERALIDADES}

En diciembre de 2019, en China, se reportaron casos llamados inicialmente «neumonía de origen desconocido». El 07 de enero las autoridades chinas identificaron como agente causante del brote un nuevo virus de la familia Coronaviridae, que posteriormente fue denominado SARS-CoV-2. La secuencia genética fue compartida por las autoridades chinas el 12 de enero. La enfermedad causada por este nuevo virus se conoce ahora como COVID-19. ${ }^{1}$

EI nuevo coronavirus SARS-CoV-2 se ha convertido en una pandemia que avanza a pasos agigantados afectando a más de 180 países. La enfermedad ha sido particularmente severa en países como EUA, España, Italia, Francia, China y Reino Unido. ${ }^{2}$ En América Latina, Brasil es el país más comprometido, seguido de Chile, Ecuador, Perú, México, Panamá y Colombia. ${ }^{3}$ De manera simultánea, los países tropicales y áreas subtropicales enfrentan otra patología, considerada un problema de salud pública: el dengue. Se estima que 3,900 millones de personas viven en países endémicos de dengue, 400 millones de infecciones se presentan cada año, de éstos 96 millones son sintomáticas, 500,000 personas presentan dengue grave y requieren hospitalización y $2.5 \%$ fallecen. El panorama de dengue

Financiamiento: Ninguno.

Conflicto de intereses: Ninguno.

https://dx.doi.org/10.35366/95646

Rev Latin Infect Pediatr 2020; 33 (3): 119-121 en las américas muestra tendencia al aumento, viviendo lo que las autoridades reportan como la mayor epidemia en los últimos 10 años. Para el 2020 relacionan 248,665 casos y 232 muertes. Colombia no es ajena a este panorama, de hecho, el año 2019 fue hiperepidémico, con un acumulado de 127,553 casos, pico epidemiológico que se mantuvo en los primeros periodos del año 2020. Hasta la semana epidemiológica nueve de 2020 , se registraron 43,000 casos; $46.1 \%$ sin signos de alarma, $52.8 \%$ con signos de alarma y $1.1 \%$ de dengue grave, con 82 muertes relacionadas a éste. ${ }^{4}$

\section{¿PUEDE EXISTIR UNA COINFECCIÓN DENGUE Y COVID-19?}

La pandemia de COVID-19 se extiende sobre territorios que ya estaban luchando contra el dengue.

Al preguntarnos si pueden coexistir las dos infecciones, lo primero que se debe aclarar es que la coinfección de los arbovirus y el COVID-19 no ha sido bien estudiada y es demasiado temprano para saber cómo van a interactuar. ¿Diríamos que una patología no descarta la otra, comparten síntomas e, incluso, se podrían potenciar?

Publicaciones recientes que provienen de la India ${ }^{5}$ sostienen que los países endémicos para dengue (los situados por debajo de los 2,200 metros sobre el nivel del mar) presentan menos infecciones por COVID-19 y menor transmisión de la enfermedad. Comparan las infecciones y muertes por COVID-19 en un país endémico para dengue, la India: 1,366 millones de habitantes, 900 casos infectados y 20 
muertes, con China 1,433 millones de habitantes 80,000 infectados y 3,295 muertos (abril 2020). Estos autores sugieren que los anticuerpos contra dengue pueden brindar protección cruzada contra COVID-19; que la memoria inmunológica secundaria a la exposición a dengue puede tener un impacto negativo sobre la transmisión y severidad de la infección por COVID-19 (interferencia viral) y proponen que pacientes convalecientes con títulos altos de IgG contra dengue podrían favorecer a casos severos de COVID-19. Incluso lanzan una pregunta de investigación: ¿podría la vacuna contra dengue generar anticuerpos que protegieran contra COVID19 en países no endémicos para dengue ${ }^{5}$

Al revisar la información sobre el estado actual de la pandemia, se nos hace difícil aceptar la publicación de la India, habría que esperar el comportamiento de la enfermedad; por lo pronto, los datos epidemiológicos no apoyan dicho estudio. América Latina es víctima de la epidemia de dengue más grave de los últimos años. Así lo informó en febrero del 2020 la Organización Panamericana para la Salud, ${ }^{6}$ OPS, alertó que en el 2019 se registró el mayor número de casos en el continente: $3,139,335$ personas infectadas y 1,538 defunciones. Según el informe de la OPS, en el 2019 se notificaron en Brasil 2,226,865 casos de dengue, incluidas 789 defunciones y, hasta ese momento, era el país que presentaba el mayor número de pacientes infectados por COVID-19: 33,000 y 2,140 muertos ${ }^{7}$ (abril 2020). La ciudad de Guayaquil, capital del estado de Guayas en la República del Ecuador, vive una tragedia, con informes de cadáveres abandonados en las calles, presentando en el momento $82.7 \%$ de los casos de COVID-19 en dicho país, junto con el mayor número de casos de dengue (84\%). ${ }^{8}$ En Ecuador se registran 403 fallecidos a causa del virus y otros 632 muertos probablemente relacionados con COVID-19.

\section{DIAGNÓSTICO DIFERENCIAL}

Desde el punto de vista clínico, el dengue y el COVID-19 comparten algunas características que dificultan su diagnóstico diferencial. Ambas enfermedades presentan una gran similitud con relación a los eventos fisiopatológicos, así como signos y síntomas, incluyendo la erupción maculopapular característica del dengue, ya reportado en casos de pacientes con COVID-19. ${ }^{9}$ El problema se incrementa debido a que la infección por COVID-19 puede ocasionar falsos positivos en las pruebas de cribado para dengue. Algunos autores describen casos que fueron diagnosticados como dengue y posteriormente confirmados como COVID-19, ${ }^{10}$ lo cual resulta en un retraso en el diagnóstico de la infección por COVID-19 y una mayor diseminación del virus, debido a que en la mayor parte de los casos de dengue no se presentan signos de alarma y el control es ambulatorio.

Ante la cocirculación viral y la ocasional dificultad para diferenciar las dos enfermedades a través de la clínica o con pruebas de laboratorio, es claro que se requieren protocolos de atención para el abordaje clínico de pacientes en zonas endémicas, que incluya un estudio cribado tanto para dengue como para COVID-19 en todos los pacientes con cuadros febriles, reforzando el concepto de que el diagnóstico de COVID-19 se debe considerar en un paciente con fiebre y prueba rápida positiva para dengue, en especial si la evolución clínica no es satisfactoria o se acompaña de signos o síntomas respiratorios. ${ }^{11}$

Otro punto a considerar es la necesidad de personal médico, paramédico y la capacidad de los países para brindar la mejor atención hospitalaria a los enfermos con estas dos patologías. En pacientes con diagnóstico de dengue, sólo 1\% requiere Unidad de Cuidado Intensivo. Sin embargo, el brote actual de dengue que ha ocasionado la hospitalización de más de 17 mil personas en Colombia es grave para la red hospitalaria, ahora que la prioridad es el coronavirus. No sólo porque la atención de médicos y enfermeros debe dividirse, sino porque hay riesgo de que la capacidad instalada no alcance para tantos pacientes.

En lo que respecta a COVID-19, los estimados de la máxima autoridad sanitaria muestran que cerca de $15 \%$ de las personas que se contagien del virus presentarán una condición que requerirá atención médica especial, mientras que 5\% entraría en una condición crítica que demandará el uso de equipos de respiración. Los adultos mayores de 60 años, que según datos de las Naciones Unidas representan 9\% de la población mundial, son los más vulnerables. Esto nos obliga a preguntarnos si, con un sistema de salud ya debilitado por el dengue y otros problemas de salud pública, entre otras dificultades políticas y sociales, los países de nuestra región están en capacidad de brindar la atención necesaria a todos los pacientes que requieran cuidados críticos.

En conclusión, COVID-19 llega a nuestra región en forma inoportuna para generarle dificultades a un sistema de salud que hasta hace poco libraba una 
Rev Latin Infect Pediatr 2020; 33 (3): 119-121

batalla con un enemigo ya conocido que siempre nos ha causado grandes heridas. Es así como debemos continuar esta histórica batalla, mientras permanecemos atrincherados diseñando la mejor estrategia para defendernos de esta nueva amenaza.

\section{REFERENCIAS}

1. Qun Li, Xuhua Guan, Peng Wu et al. Early transmission dynamics in Wuhan, China, of novel coronavirus infected pneumonia. NEJM [Internet]. 2020. [21 April 2020] volumen [382] 1199-1207. Available in: https://www.nejm.org/doi/ full/10.1056/NEJMoa2001316.

2. WHO [Internet]. New York. WHO: 2020 Coronavirus. 2020. [Citado 20 de marzo de 2020] Disponible en: https://www. who.int/health-topics/coronavirus.

3. Talha Burki reports. COVID-19 in Latin America, several problems undermine the preparedness of countries in Latin America to face the spread of COVID-19. The Lancet Infectious Disease [Internet]. 2020 [21 April 2020]; 2 Available in: https://www.thelancet.com/pdfs/journals/laninf/ PIIS1473-3099(20)30303-0.pdf.

4. Instituto Nacional de Salud [Internet]. Colombia. GOV.CO. 2020 [2 de abril de 2020] Disponible en: https://www.ins. gov.co/Noticias/Paginas/Dengue.aspx.

5. Subhajit Biswas, Soumi Sukla. COVID-19 virus infection and transmission are observably less in highly Dengueendemic countries: Can Dengue vaccines be "repurposed" to prevent COVID-19? OSFPreprints [Internet]. 2020 (15) 1-15. Available in: https://osf.io/dzygw/.

6. OPS [Internet]. USA. OPS/OMS.2020 [14 de febrero de 2020; 2 de abril de 2020] Disponible en: https://www.paho.org/hq/index.php?option=com docman\&view=download\&category_slug=coronavirusalertas-epidemiologicas $\&$ alias $=51759$ - 14 -de-febrerode-2020-nuevo-coronavirus-covid-19-actualizacionepidemiologica-2\&ltemid=270\&lang=es.

7. Azevedo LC. TS COVID-19 and dengue fever, a dangerous combination for the health system in Brazil. Travel Medicine and Infectious Disease [Internet]. 2020. [21 Abril 2020]; 2. Available in: https://doi.org/10.1016//j.tmaid2020.101659

8. Navarro JC, Arrivillaga-Henríquez J. COVID-19 and dengue, co-epidemics in Ecuador and other countries in Latin America: Pushing strained health care systems over the edge. Travel Medicine and Infectious Disease. [Internet]. 2020. [08 April 2020]; 2 Available in: https://doi.org/10.1016/ tmaid.2020.101656

9. Jimenez-Cauhe J. COVID 19 can present with a rash and be mistaken for dengue. J Am Acad Dermatol [Internet]. 2020. [09 April 2020]; 1-8 Available in: https://doi.org/10.1016/j. jaad.2020.04.016.

10. Yan G, Lee CK, Lam LT, Yan B, Chua YX, Lim AY, Lin L. Covert COVID-19 and false-positive dengue serology in Singapore. Lancet Infect Dis. [Internet]. 2020. [09 April 2020]; 1-8 Available in: https://www.thelancet.com/journals/ laninf/article/PIIS1473-3099(20)30158-4/fulltext.

11. Saavedra. V. Revista de la Facultad de Ciencias Médicas de Córdoba [Internet]. 2020. [09 Abril 2020]; 77 (1): 52-54 Disponible en: https://revistas.unc.edu.ar/index.php/med.

Correspondencia:

Pío López, MD

E-mail: pio.lopez@ceiponline.org 